\title{
Evaluation of factors influencing stable microbubble test results in preterm neonates at 30-33 gestational weeks
}

This article was published in the following Dove Press journal:

Research and Reports in Neonatology

20 February 2012

Number of times this article has been viewed

\section{Oxana A Tesloval,2 \\ Takehiko Hiroma' \\ Elena I Baranovskaya ${ }^{2}$ \\ Tomohiko Nakamura' \\ 'Division of Neonatology, Nagano Children's Hospital, Azumino City, Nagano, Japan; ${ }^{2}$ Department of Obstetrics and Gynecology, Gomel State Medical University, Belarus}

Correspondence:Tomohiko Nakamura 3100 Toyoshina, Azumino City, Nagano 399-8288, Japan

Tel +81263736700

Fax $+8 I 263735432$

Email tnakamura@naganoch.gr.jp
Background: The stable microbubble test (SMT) is a sensitive and specific means of predicting respiratory distress syndrome in newborns, using quantitative correlations with concentrations of the protein and lipid components of surfactant. We hypothesized that fetal nutrition would affect the synthesis of surfactant components. The objectives of this study were to evaluate aspects of fetal and maternal nutrition influencing SMT results and related to development of respiratory distress syndrome in preterm neonates.

Methods: Data from 194 preterm neonates of gestational age 23-36 weeks were analyzed using multivariate regression modeling to identify factors influencing SMT results. After adjusting for gestational age, we compared obstetric, maternal, neonatal, and placental data using analysis of variance in 99 neonates at 30-33 weeks of gestation based on results of the SMT. Receiver-operating-characteristic analysis was performed to characterize factors predictive of respiratory distress syndrome.

Results: SMT results were most strongly associated with the concentration of protein in neonatal blood $(P<0.05)$ and maternal weight gain during pregnancy $(P<0.05)$. Cutoff values for predicting respiratory distress syndrome were serum protein $<4.7 \mathrm{~g} / \mathrm{L}$ and maternal weight gain $<200 \mathrm{~g} /$ week.

Conclusion: Inadequate maternal weight gain during pregnancy may play a significant role in immaturity of the surfactant system in the lungs and may be a predictor of respiratory distress syndrome in premature babies.

Keywords: stable microbubble test, respiratory distress syndrome, protein concentration, gestational weight gain

\section{Introduction}

Respiratory distress syndrome is one of the most important causes of morbidity in preterm neonates, ${ }^{1,2}$ and causes the development of bronchopulmonary dysplasia. ${ }^{3}$ The severity of respiratory distress syndrome depends on the deficiency or dysfunction of pulmonary surfactant. ${ }^{4}$ Synthesis of surfactant from serum products in the fetus starts from 20-24 weeks of gestation and increases dramatically toward the end of pregnancy, depending on the influence of corticosteroids, thyrotropin, cyclic adenosine monophosphate, prostaglandins, and epidermal growth factor. Pulmonary surfactant is synthesized by type II alveolocytes, and includes phospholipid (dipalmitoyl phosphatidylcholine, phosphatidylcholine, phosphatidylglycerol, and phosphatidylinositol) and protein (surfactant proteins A, B, C, and D) components. This lipid-protein layer decreases the surface tension of the alveoli after birth, protecting against the development of respiratory distress syndrome. ${ }^{5}$ Absence or abnormality of even one component 
of the normal surfactant composition increases the possibility of respiratory failure. ${ }^{6-8}$ The stable microbubble test (SMT) ${ }^{9}$ is a very sensitive and specific means of predicting respiratory distress syndrome in newborns. ${ }^{10,11}$ Recent studies have shown quantitative correlations of SMT results with concentrations of surfactant phospholipids and proteins. ${ }^{12-18}$ We hypothesized that fetal nutrition would affect the synthesis of surfactant components. The objectives of this study were to evaluate fetal and maternal nutrition factors influencing the results of SMT and related to the development of respiratory distress syndrome in preterm neonates.

\section{Materials and methods}

\section{Data collection}

We undertook a retrospective analysis of medical documents from 557 preterm neonates born at Nagano Children's Hospital (Azumino City, Nagano, Japan) and their mothers from January 2006 to December 2009. Inclusion criteria were performance of SMT and a verified diagnosis of respiratory distress syndrome or transient tachypnea of newborns. Exclusion criteria included stillbirth, presence of congenital or chromosomal abnormalities, and presence of severe disease requiring surgery in the early neonatal period or neonatal sepsis. As a result, 194 neonates from 154 mothers were included in the study. All study protocols were approved by the ethics committee of Nagano Children's Hospital. The study examined:

- Obstetric data, ie, duration of gestation at delivery, membrane rupture, and administration of tocolytics (ritodrine, magnesium sulfate) and corticosteroids (dexamethasone) in the antenatal period

- Neonatal data, ie, gender, morphometrics (weight, length, head and chest circumference), Apgar score (at 1 and 5 minutes), blood hematology (red blood cells, white blood cells, platelets) and biochemistry (total protein, albumin, blood urea nitrogen, creatinine, total bilirubin, aspartate aminotransferase, alanine aminotransferase, lactate dehydrogenase, creatine kinase, C-reactive protein, and immunoglobulins $\mathrm{G}$ and $\mathrm{M}$ )

- Maternal data, ie, age, height, weight, total gestational weight gain, blood hematology (red blood cells, white blood cells, platelets) and biochemistry (total protein, albumin, blood urea nitrogen, creatinine, total bilirubin, aspartate aminotransferase, alanine aminotransferase, lactate dehydrogenase, creatine kinase, C-reactive protein)

- Placental data, ie, histological examination of the placenta, weight, inflammation. Respiratory distress syndrome was defined based on the results of SMT and/or X-ray (granule appearance). SMT was performed using newborn gastric fluid obtained during resuscitation. We also calculated intrauterine growth retardation ${ }^{19}$ and body mass index ${ }^{20}$ in mothers before pregnancy, mean gestational weight gain per week, placental-fetal weight ratio, ${ }^{21}$ mean placental weight gain per week, and hypo/ hyperplasia of the placenta. $^{22}$

\section{Study design}

All newborns were initially divided into five groups based on the results of SMT. Multivariate regression analysis was used to identify factors contributing to SMT results. Because the most influential factor was gestational age, we decided to perform a further analysis using comparable groups. We then divided the whole cohort into six groups according to gestational age and chose two paramedian groups with gestational ages of 30-31 weeks $(n=45)$ and 32-33 weeks $(n=54)$ as the most homogenous (Figure 1).

\section{Statistical analysis}

Continuous variables are presented as the median with the interquartile range, while categorical variables are presented

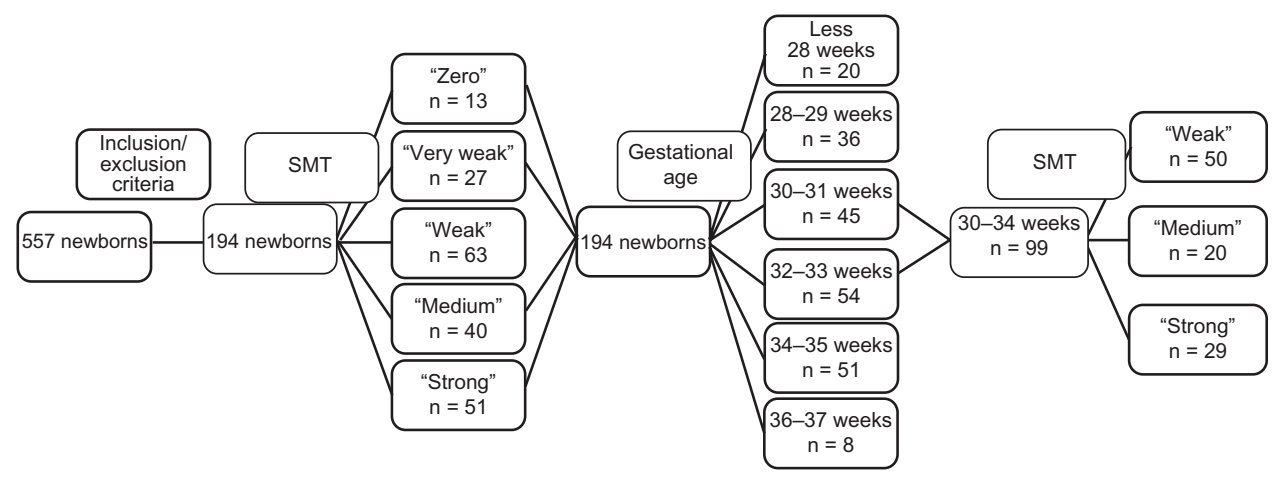

Figure I Study design using the stable microbubble test. 
as numbers (n) and percentages (\%). Continuous variables were compared between several groups using KruskalWallis one-way analysis of variance $(\mathrm{H})$, with post hoc comparisons using the Mann-Whitney $U$-test. The rank correlation gamma test was used to identify correlations between variables. Categorical variables were compared using the Pearson $\chi^{2}$ test or Fisher's Exact test. Regression multivariate analysis $(\beta)$ was performed to examine factors associated with SMT results.

Receiver-operating characteristic (ROC) curves were constructed to assess the sensitivity, specificity, and cutoff values of variable measurements to compare abilities to diagnose respiratory distress syndrome. Comparisons of the area under the ROC curve were performed. For all analyzed variables, we calculated the positive predictive value, negative predictive value, and likelihood ratio for cutoff points. Values of $P<0.05$ were considered to indicate statistical significance. All statistical analyses were performed using Statistica for Windows software (v 6.0; StatSoft, Inc, Tulsa, OK) and MedCalc software (v 11.2.1; MedCalc, Mariakerke, Belgium).

\section{Results}

After dividing all newborns into five groups, multivariate regression models identified the best values for predicting the results of SMT as:

- Gestational age $(\beta=0.63, P=0.000025)$ from neonatal data

- Total protein concentration $(\beta=0.562, P=0.024)$ from neonatal blood biochemistry

- White blood cells $(\beta=0.22, P=0.009)$ from neonatal blood data

- Gestational weight gain $(\beta=2.4, P=0.00001)$ and mean gestational weight gain per week $(\beta=2.2, P=0.00001)$, from maternal data

- Concentrations of albumin $(\beta=0.54, P=0.003)$, blood urea nitrogen $(\beta=0.50, P=0.003)$ and creatinine $(\beta=0.48$, $P=0.005)$, from maternal blood biochemistry

- Placental weight $(\beta=0.717, P=0.00001)$ and placental weight gain per week $(\beta=0.4, P=0.017)$.

We did not identify any significant associations with gender distribution, multiple pregnancies, intrauterine growth retardation, frequency of preterm rupture of membranes, placental pathology, method of delivery, or antenatal administration of tocolytics or corticosteroids.

The new cohort of 99 newborns was divided into three groups according to the quantity of stable microbubbles: "weak", $<10 / \mathrm{mm}^{2}$; "medium", 10-20/mm²; or "strong", $>20 / \mathrm{mm}^{2}$. These new groups showed no significant differences in gestational age $(\mathrm{H}=5.48, P=0.065)$, gender of the neonate, multiple pregnancies, method of delivery, or premature rupture of membranes. The frequency of administration of tocolytics or corticosteroids in the antenatal period was comparable between groups. Placental characteristics were the same in all groups.

The results showed respiratory distress syndrome in 44 newborns $(88.0 \%)$ from the "weak" group, seven $(35.0 \%)$ from the "medium" group, and three (10.3\%) from the "strong" group. Among neonates without respiratory distress, intrauterine growth retardation tended to be more frequent, with 17 (37.7\%) compared with $11(20.4 \%)$ in the respiratory distress syndrome group $\left(\chi^{2}=3.67, P=0.055\right)$.

The results of blood analysis are shown in Table 1. Significant differences in protein concentration were observed when comparing groups. Concentrations of protein were significantly linked with the results of SMT. A similar significance was observed for albumin concentration.

A negative correlation was observed between the concentration of aspartate aminotransferase and the number of stable microbubbles in the test $(\gamma=-0.32, P=0.002)$. Statistical analysis showed significant differences in creatine kinase levels, but no stable pattern of distribution between the groups was observed and the negative correlation with SMT was significant.

No significant differences were evident for maternal age, weight before pregnancy, height, body mass index, results of biochemical analysis, or blood data. However, differences were seen between the groups for weight gain during pregnancy (gestational weight gain, $\mathrm{H}=11.49$, $P=0.003$ ) and weight gain per week (mean gestational weight gain per week, $\mathrm{H}=9.97, P=0.007$ ), with both being strongly correlated with SMT results $(\gamma=0.31$, $P=0.005$ and $\gamma=0.29, P=0.009$, respectively). Placental weight gain per week for singletons after adjusting for absence of edema was $138 \mathrm{~g} /$ week (interquartile range 80-191 g/week) in the "weak" group, $135.5 \mathrm{~g} /$ week (interquartile range 74-221 g/week) in the "medium" group, and $221 \mathrm{~g} /$ week (interquartile range 169-285 g/week) in the "strong" SMT group.

ROC analysis was used to compare the predictive characteristics of total protein, aspartate aminotransferase, creatine kinase determination, and maternal mean gestational weight gain per week for respiratory distress in newborns (Figure 2).

Determination of protein concentrations in the serum of preterm infants offered sensitivity and specificity comparable 
Table I Results of blood analysis in newborns at 30-33 weeks of gestation according to results of the stable microbubble test

\begin{tabular}{|c|c|c|c|c|c|}
\hline \multirow[t]{4}{*}{ Parameter } & \multicolumn{3}{|l|}{ SMT } & \multicolumn{2}{|l|}{ Statistics } \\
\hline & Weak & Medium & Strong & Criteria & $P$ value \\
\hline & $\mathbf{n}=\mathbf{5 0}$ & $\mathbf{n}=\mathbf{2 0}$ & $\mathbf{n}=\mathbf{2 9}$ & & \\
\hline & I & 2 & 3 & & \\
\hline \multicolumn{6}{|c|}{ Biochemical blood analysis (median, IQR) } \\
\hline \multirow[t]{2}{*}{ Total protein, g/dL } & $4.5(4.3-4.8)$ & $4.7(4.2-5.2)$ & $5.1(4.3-5.6)$ & $\mathrm{H}=7.0$ & 0.030 \\
\hline & & & & $Z_{1,3}=2.57$ & 0.010 \\
\hline \multirow[t]{2}{*}{ Albumin, g/dL } & $3.0(2.8-3.2)$ & $3.1(2.9-3.2)$ & $3.2(2.9-3.5)$ & $\mathrm{H}=6.74$ & 0.034 \\
\hline & & & & $Z_{1,3}=2.52$ & 0.012 \\
\hline BUN, mg/dL & $7.0(5.0-9.0)$ & $6.0(5.0-10.0)$ & $8.0(6.0-9.0)$ & $\mathrm{H}=1.0$ & 0.607 \\
\hline Creatinine, $\mathrm{mmol} / \mathrm{L}$ & $0.54(0.48-0.62)$ & $0.5 I(0.49-0.62)$ & $0.53(0.5-0.6)$ & $H=0.13$ & 0.935 \\
\hline Total bilirubin, $\mathrm{mmol} / \mathrm{L}$ & $1.8(1.7-2.3)$ & $2.1(1.9-2.2)$ & $1.9(1.7-2.3)$ & $\mathrm{H}=0.69$ & 0.708 \\
\hline \multirow[t]{2}{*}{ AST, IU/L } & $42(3 \mid-70)$ & $35(3 \mid-48)$ & $34(25-4 I)$ & $H=8.13$ & 0.017 \\
\hline & & & & $Z_{1,3}=2.73$ & 0.006 \\
\hline ALT, IU/L & $5(4-6)$ & $4(4-5.5)$ & $5(4-6)$ & $\mathrm{H}=1.29$ & 0.52 \\
\hline $\mathrm{LDH}, \mathrm{U} / \mathrm{L}$ & $529(385-721)$ & 481 (409-698) & $460(363-564)$ & $\mathrm{H}=3.16$ & 0.206 \\
\hline \multirow[t]{2}{*}{ CK, IU/L } & $339(267-4 \mid 4)$ & $264(225-342)$ & $278(195-339)$ & $\mathrm{H}=7.64$ & 0.022 \\
\hline & & & & $Z_{1,3}=2.48$ & 0.013 \\
\hline $\mathrm{CRP}, \mathrm{mg} / \mathrm{L}$ & $0.1(0-0.2)$ & $0.1(0.01-0.1)$ & $0.1(0-0.2)$ & $\mathrm{H}=0.83$ & 0.660 \\
\hline $\lg \mathrm{G}, \mathrm{g} / \mathrm{L}$ & $552(459-633)$ & $524(478-789)$ & $65 I(486-86 I)$ & $\mathrm{H}=3.95$ & 0.139 \\
\hline $\lg M, g / L$ & $8(6-9)$ & $8(7-13)$ & $8(5-10)$ & $\mathrm{H}=0.87$ & 0.647 \\
\hline \multicolumn{6}{|c|}{ Blood formula, cells (median, IQR) } \\
\hline \multirow[t]{2}{*}{ White blood cells } & 99.6 & 108.9 & 103.8 & $\mathrm{H}=2.54$ & 0.281 \\
\hline & $(65.2-134.4)$ & $(82.3-158.1)$ & $(95.2-150.2)$ & & \\
\hline Red blood cells & $442(422-483)$ & $437(388-480)$ & $458(4|3-48|)$ & $\mathrm{H}=0.8 \mathrm{I}$ & 0.668 \\
\hline Platelets & $20.9(16.5-24.9)$ & $18.0(\mid 1.9-26.5)$ & $24.5(20.4-28.0)$ & $H=4.86$ & 0.088 \\
\hline
\end{tabular}

Notes: H, Kruskal-Wallis test; Z, Mann-Whitney U-test.

Abbreviations: ALT, alanine aminotransferase; AST, aspartate aminotransferase; BUN, blood urea nitrogen; CK, creatine kinase; CRP, C-reactive protein; Ig, immunoglobulin; IQR, interquartile range; LDH, lactate dehydrogenase; SMT, stable microbubble test.

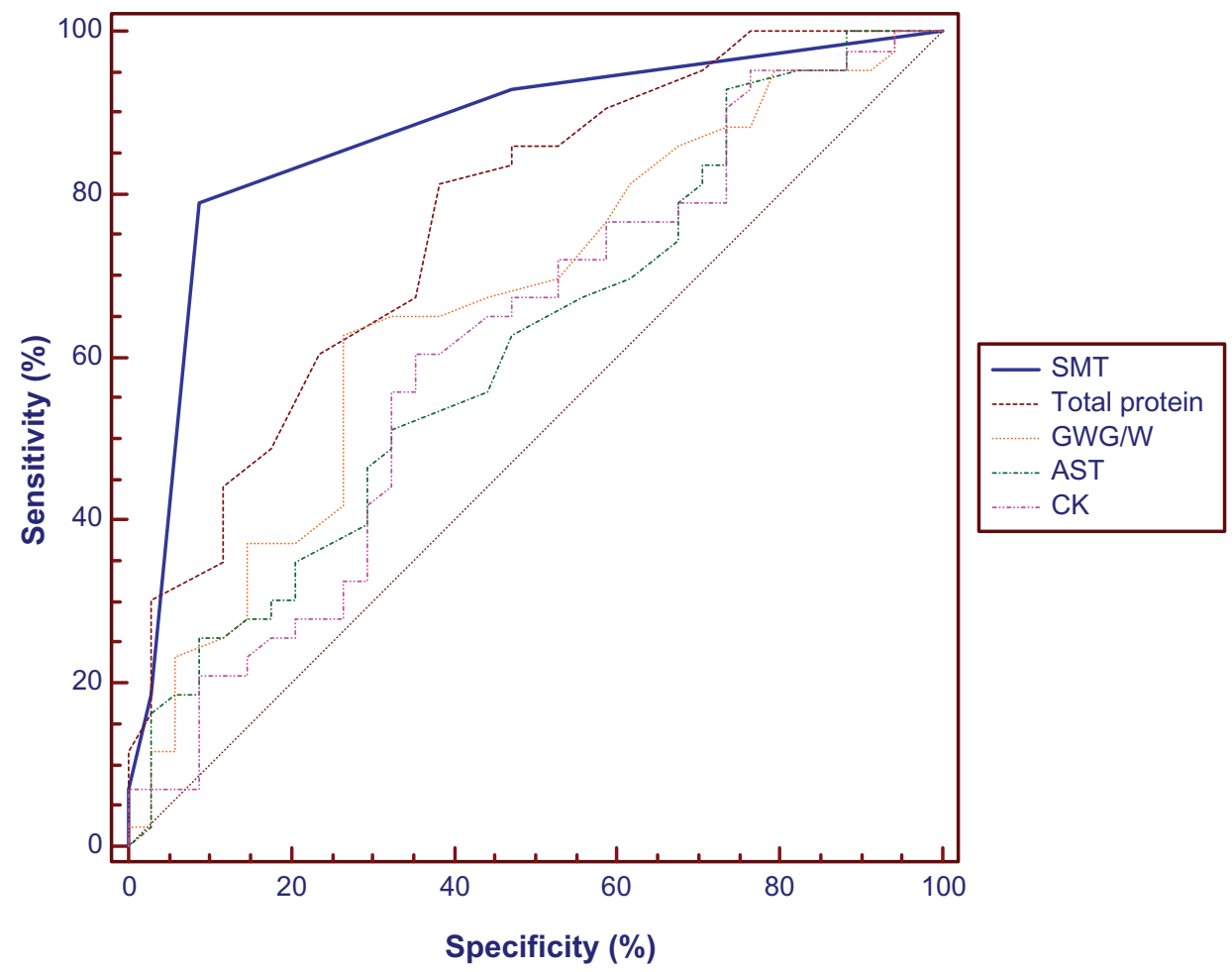

Figure 2 Receiver-operating characteristic curves for stable microbubble test, total protein, aspartate aminotransferase, creatine kinase concentration and gestational weight gain per week for predicting respiratory distress syndrome in preterm newborns at 30-33 weeks of gestation. 
Table 2 Specifications for stable microbubble test, total protein, aspartate aminotransferase, creatine kinase concentration, and gestational weight gain per week, and cutoff points in predicting respiratory distress syndrome in preterm newborns

\begin{tabular}{llllllll}
\hline Parameter & Se, $\%$ & Sp, $\%$ & PPV, \% & NPV, \% & AUC $(95 \%$ Cl) & Cutoff point & LR (95\% Cl) \\
\hline SMT & $8 I .5$ & 86.7 & 88.0 & 79.6 & $0.88(0.79-0.95)$ & $\leq 10 \mathrm{mcb}^{2} \mathrm{~mm}^{2}$ & $6.1 \mathrm{I}(2.87-13.0 \mathrm{I})$ \\
Total protein & 78.4 & 60.5 & 70.4 & 70.0 & $0.77(0.66-0.86)$ & $\leq 4.7 \mathrm{~g} / \mathrm{L}$ & $1.98(1.33-2.95)$ \\
GWG/W & 63.0 & 73.7 & 74.2 & 62.4 & $0.67(0.56-0.77)$ & $\leq 199 \mathrm{~g}$ & $2.40(1.35-4.26)$ \\
AST & 92.2 & 28.9 & 60.8 & 75.6 & $0.62(0.50-0.73)$ & $>25 \mathrm{IU} / \mathrm{L}$ & $1.29(1.06-1.59)$ \\
CK & 62.7 & 69.8 & 71.3 & 61.0 & $0.61(0.50-0.72)$ & $>315 \mathrm{IU} / \mathrm{L}$ & $2.08(1.26-3.43)$ \\
\hline
\end{tabular}

Abbreviations: AST, aspartate aminotransferase; AUC, area under the receiver-operating characteristic curve; GWG/W, gestational weight gain per week; LR, likelihood ratio; mcb, microbubbles; PPV, positive predictive value; NPV, negative predictive value; SMT, stable microbubble test; CK, Creatine phosphokinase; Se, Sensitivity; Sp, Specificity.

with that of SMT using a cutoff value of $<4.7 \mathrm{~g} / \mathrm{L}$ for predicting respiratory distress syndrome. The final specifications of these parameters and associated cutoff points are presented in Table 2.

\section{Discussion}

Modern medicine offers many opportunities for improving the prognosis for preterm neonates, including antenatal use of drugs to stimulate the synthesis of surfactant, substitution or prophylactic use of synthetic or natural surfactants immediately after birth, and various modes of ventilation support, depending on the degree of prematurity and related conditions. All these methods are available in highly developed countries.

The remaining issue is the question of antenatal prophylaxis and forecasting and reducing the risk of respiratory distress syndrome under conditions of limited resources. Surfactant components are produced by the pulmonary epithelium from the metabolism of serum proteins and lipids. Animal experiments have shown roles of maternal food deprivation and low-protein diets in potentiating lung hypoplasia and increasing surface tension in the alveoli. ${ }^{23}$ Reducing the protein content in the diet of pregnant animals results in significantly decreased concentrations of surfactant protein $\mathrm{A}$ in the fetal lungs and amniotic fluid. ${ }^{24}$ Animals fed a high-fat, carbohydrate-free diet show decreased lung concentrations of phospholipids and increases in cholesterol. ${ }^{25}$ Studies have also demonstrated the importance of an adequate supply of vitamins, minerals, and carbohydrates to the pregnant animal for the normal maturation of lung tissue. ${ }^{26,27}$

In a retrospective survey of social and health factors among preterm neonates, considerable gestational weight gain halved the risk of respiratory distress syndrome. ${ }^{28} \mathrm{In}$ prospective studies among pregnant women, adequate perinatal nutrition (3000-4000 kcal/day) and education programs on neonatal outcomes have been associated with a shorter duration of ventilator support in neonates. ${ }^{29}$
Low concentrations of lipids in the serum of pregnant women have shown a relationship with decreased concentrations of total cholesterol and high-density and low-density lipoproteins, with subsequent development of respiratory distress syndrome in newborns. In turn, the level of lowdensity lipoprotein in infants is related to gestational weight gain. ${ }^{30}$ Concentrations of low-density lipoprotein and triglycerides are reduced in the cord blood of preterm neonates, which could be associated with the development of respiratory distress syndrome. ${ }^{31}$

Balanced nutrition during pregnancy thus seems to play a role in ensuring structural and functional maturity of the fetal lung. In our view, studies of protein, lipid, and carbohydrate metabolism in pregnant women with preterm delivery will facilitate a better understanding of the pathogenetic basis for the development of respiratory distress syndrome in newborns and allow the establishment of a system of preventive measures.

The present study shows that SMT results are linked most strongly to concentrations of protein in neonatal blood and gestational weight gain. Inadequate gestational weight gain may play a significant role in immaturity of the pulmonary surfactant system and may thus offer a predictor of respiratory distress syndrome in premature babies. These results suggest that adequate nutritional guidance for pregnancy is important to prevent neonatal respiratory failure, and that perinatal information about pregnant women with poor weight gain may allow preparation for aggressive respiratory support for premature infants, including surfactant replacement therapy.

\section{Acknowledgments}

This study was funded by a grant for scientific research from the Ministry of Health, Labor, and Welfare of Japan. OAT was supported by the Chernobyl Medical Fund.

\section{Disclosure}

The authors report no conflicts of interest in this work. 


\section{References}

1. Lee K, Khoshnood B, Wall SN, Chang Y, Hsieh H-L, Singh JK. Trend in mortality from respiratory distress syndrome in the United States, 1970-1995. J Pediatr. 1999;134:434-440.

2. Stoelhorst GMSJ, Rijken M, Martens SE, et al. Changes in neonatology: comparison of two cohorts of very preterm infants (gestational age $<32$ weeks): the project on preterm and small for gestational age infants 1983 and the Leiden follow-up project on prematurity 1996-1997. Pediatrics. 2005; 115:396-405.

3. Northway WH. Bronchopulmonary dysplasia: twenty-five years later. Pediatrics. 1992;89:969-973.

4. Carnieli VP, Zimmermann LJI, Hamvas A, Cogo PE. Pulmonary surfactant kinetics of the newborn infant: novel insights from studies with stable isotopes. J Perinatol. 2009;29:S29-S37.

5. Polin RA. The Newborn Lung: Neonatology Questions and Controversies. Philadelphia, PA: Saunders Elsevier; 2008.

6. Hallman M, Merrit TA, Akino T, Bry K. Surfactant protein A, phosphatidylcholine, and surfactant inhibitors in epithelial lining fluid. Correlation with surface activity, severity of respiratory distress syndrome, and outcome in small premature infants. Am Rev Respir Dis. 1991;144:1376-1384

7. Kaneko K, Shimizu H, Arakawa H, Ogawa Y. Pulmonary surfactant protein A in sera for assessing neonatal lung maturation. Early Hum Dev. 2001;62:11-21.

8. Nogee LM, Wert SE, Proffit SA, Hull WM, Whitsett JA. Allelic heterogeneity in hereditary surfactant protein B (Sp-B) deficiency. Am J Respir Crit Care Med. 2000;161:973-981.

9. Patle RE, Kratzing CC, Parkinson CE, et al. Maturity of fetal lungs tested by production of stable microbubbles in amniotic fluid. $\mathrm{Br} J$ Obstet Gynaecol. 1979;86:615-622.

10. Chida S, Fujiwara T, Konishi M, Takahasi H, Sasaki M. Stable microbubble test for predicting the risk of respiratory distress syndrome: II. Prospective evaluation of the test on amniotic fluid and gastric aspirate. Eur J Pediatr. 1993;152:152-156.

11. Fiori HH, Henn R, Baldisserotto M, Bica IG, Fiori RM. Evaluation of surfactant function at birth determined by the stable microbubble test in term and near term infants with respiratory distress. Eur J Pediatr. 2004;163:443-448.

12. Chida S, Fudjiwara T. Stable microbubble test for predicting the risk of respiratory distress syndrome: I. Comparisons with other predictors of fetal lung maturity in amniotic fluid. Eur J Pediatr. 1993;152:148-151.

13. Fiori HH, Fritcher CC, Fiori RM. Selective surfactant prophylaxis in preterm infants born at $\leq 31$ weeks' gestation using the stable microbubble test in gastric aspirates. J Perinat Med. 2006;34:66-70.

14. Kumazawa K, Hiramatsu Y, Masuyama H, Mizutani Y, Nakata T, Kudo T. Prediction markers for respiratory distress syndrome: evaluation of the stable microbubble test, surfactant protein-A and hepatocyte growth factor levels in amniotic fluid. Acta Med Okayama. 2003;57:25-32.
15. Boo NY, Cheong KB, Cheong SI, Lye MS, Zulfiquar MA. Usefulness of stable microbubble test of tracheal aspirate for the diagnosis of neonatal respiratory distress syndrome. J Paediatr Child Health. 1997;33:329-334.

16. Gotoh K, Higuchi M, Maki M. Prenatal assessment of fetal lung maturity by the stable microbubble method - fundamental study. Nippon Sanka Fujinka Gakkai Zasshi. 1985;37:220-228. Japanese.

17. Cheong KB, Cheong SK, Boo NY. Surfactant protein A and stable microbubble formation in tracheal aspirates. Malays J Pathol. 1996;18:101-105.

18. Otsubo E, Takei T. Characterization of the surface activity of a synthetic surfactant with albumin. Biol Pharm Bull. 2002;25:1519-1523.

19. Rennie JM, editor. Roberton's Textbook of Neonatology. 4th ed. London, UK: Elsevier Churchill Livingstone; 2005.

20. Taeusch W, Ballard R. Avery's Diseases of the Newborn. Sunders. Philadelphia USA. 7th edition. 1998.

21. Pardi G, Marconi AM, Cetin I. Placental-fetal interrelationship in IUGR fetuses. Placenta. 2002;23:S136-S141.

22. Thompson JMD, Irgens LM, Skjaerven R, Rasmussen S. Placenta weight percentile curves for singleton deliveries. BrJ Obstet Gynaecol. 2007; 114:715-720.

23. Farridy EE. Effect of the maternal malnutrition on surface activity of fetal lungs in rats. J Appl Physiol. 1975;39:535-540.

24. Kohri T, Sakai K, Mizunuma T, Kishino Y. Levels of pulmonary surfactant protein $\mathrm{A}$ in fetal lung and amniotic fluid from proteinmalnourished pregnant rats. J Nutr Sci Vitaminol. 1996;42:209-218.

25. Ojeda MS, Gomez N, Gimenes MS. Effects of the diet consumed during the pregnancy on the lipid content in maternal and fetal rat lung. Biol Res. 1992;25:27-30.

26. Abdel-Mageed AB, Welti R, Oehme FW, Pickrel JA. Perinatal hypocuprosis affects synthesis and composition of neonatal lung collagen, elastin, and surfactant. Adv Physiol Educ. 1994;267:L679-L685.

27. Chailley-Heu B, Chelly N, Lelievre-Pegorier M, Barlier-Mur AM, Merlet-Benichou C, Bourbon JR. Mild vitamin A deficiency delays fetal lung maturation in the rat. Am J Respir Cell Mol Biol. 1999;21: 89-96.

28. Borkowski W, Mielniczuk H. Social and health factors of respiratory distress syndrome in preterm infants. Ginekol Pol. 2007;78:856-860. Polish.

29. Luke B, Brown MB, Misiunas R, et al. Specialized prenatal care and maternal and infant outcomes in twin pregnancy. Am J Obstet Gynecol. 2003;189:934-938.

30. Gunes T, Koklu E, Ozturk MA. Maternal and cord serum lipid profiles of preterm infants with respiratory distress syndrome. J Perinatol. 2007;27:415-421.

31. Yonezawa R, Okada T, Kitamura T, et al. Very low-density lipoprotein in the cord blood of preterm neonates. Metabolism. 2009;58:704-707.
Research and Reports in Neonatology

\section{Publish your work in this journal}

Research and Reports in Neonatology is an international, peer-reviewed, open access journal publishing original research, reports, editorials, reviews and commentaries on neonatal health. The manuscript management system is completely online and includes a very quick and fair

\section{Dovepress}

peer-review system. Visit http://www.dovepress.com/testimonials.php to read real quotes from published authors. 